\title{
The diagnosis and management of interstitial ectopic pregnancies: a review
}

\author{
Maximilian Brincat ${ }^{*}$ D, Alison Bryant-Smith and T. K. Holland
}

\begin{abstract}
The objective of this article is to review the published literature on the diagnosis and management of interstitial pregnancies (IPs). IPs account for 2-6\% of all ectopic pregnancies and have the potential to cause life-threatening haemorrhage resulting in a $2-5 \%$ mortality rate. There is little consensus on the best practice for diagnosing and managing interstitial pregnancies. By reviewing the published data, we set out to determine what the best evidencebased practice for the management of interstitial ectopic pregnancies is, what protocols can be used and whether this improves post-operative outcomes and future fertility rates.
\end{abstract}

Keywords: Interstitial ectopic pregnancy, Methotrexate, Cornuostomy, Wedge resection, Fertility

\section{Introduction}

The diagnosis and management of interstitial pregnancies (IPs) remains challenging, largely due to the rarity of this diagnosis. Most units are likely to manage only one or two cases per year. Appropriate first line management is based on many factors, including the patient's symptoms, timely diagnosis, size of the pregnancy, depth of surrounding myometrium, haemodynamic stability, and desires for future fertility.

There is limited evidence on interstitial pregnancies and their management with current evidence consisting of small case series with no randomised controlled trials (RCTs). This review will perform a comprehensive and systematic review of the current evidence regarding the diagnosis and management of interstitial pregnancies, to help work toward a consensus on the appropriate management of such cases.

\section{Definition, incidence, and pathophysiology}

An interstitial pregnancy (IP) occurs when the blastocyst implants in the most proximal section of the fallopian tube (called the interstitial portion), which is within the myometrium [1]. This interstitial section of the fallopian tube is approximately $0.7-\mathrm{mm}$ wide and 1-2-cm long [2].

\footnotetext{
* Correspondence: maxbrincat@gmail.com

Department of Women's Health, Guy's and St Thomas' NHS Trust, St Thomas' Hospital, Westminster Bridge Road, Lambeth, London SE1 7EH, UK
}

IPs may be incorrectly referred to as 'cornual' or 'angular' pregnancies. It is important to correctly differentiate between these terms, as the resultant maternal morbidity and mortality vary greatly. An 'angular pregnancy' occurs when an embryo is implanted medial to the utero-tubal junction, in the lateral angle of the uterine cavity, and as such is neither an ectopic pregnancy nor dangerous (Fig. 1). Cornual implantation describes those in the upper and lateral uterine cavity, whereas interstitial denotes those blastocysts implanted within the proximal intramural portion of the tube [1]. Therefore a 'cornual pregnancy' is any pregnancy which is implanted in the horn of a uterus, which may be one horn of a bicornuate uterus, which is not an ectopic pregnancy [3] or a non-communicating, functional rudimentary cornua of a unicornuate uterus, which is an ectopic pregnancy (Mavrelos et al. 2007). Because the term 'cornual' can be applied to many different types of pregnancy, it should be avoided when discussing interstitial ectopic pregnancies.

The incidence of ectopic pregnancies is generally increasing; there also appears to be a concurrent increase in the proportion of ectopic pregnancies that are IPs. The increase in incidence of IPs may be due to various factors, including better diagnosis, more prevalent pelvic inflammatory disease, pelvic surgery, and assisted reproductive techniques $[3,4]$. IPs account for $2-6.8 \%$ of all ectopic pregnancies [5-7]. 


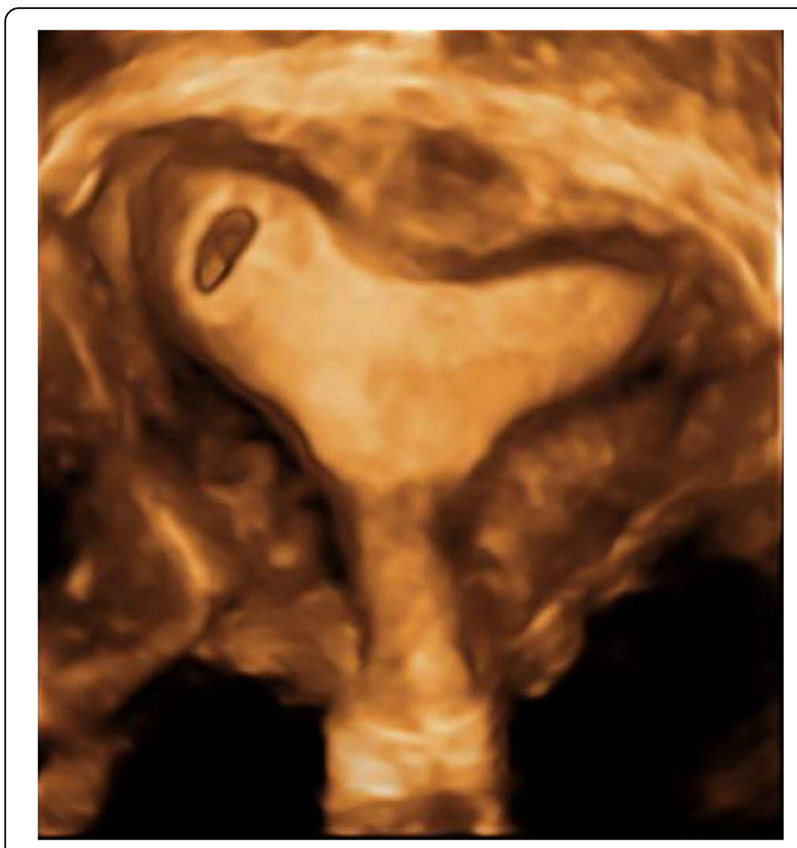

Fig. 1 US image of angular pregnancy

Historically IPs were diagnosed at laparotomy after rupture at the end of the first trimester or early in the second trimester, and hysterectomy rates were as high as $40 \%$ [8]. However, the outcome from this diagnosis has improved more recent case series that have estimated a mortality rate of $2-2.5 \%$, which is seven times the average for all ectopic pregnancies [7]. The increased morbidity and mortality is due to catastrophic bleeding secondary to rupture, due to the close proximity of the gestational sac (GS) to the intramyometrial arcuate vasculature [3]. It is also likely that IPs are larger when they rupture than tubal ectopic pregnancies as the layer of overlying myometrium is able to accommodate larger pregnancies, before rupture, than the uterine tube.

\section{Methodology}

A literature search was carried out in March 2018 using key words 'interstitial pregnancy', 'cornual pregnancy' and 'angular pregnancy'. Articles that were published from January 2000 until March 2018 were obtained from MEDLINE, EMBASE and PUBMED. This systematic search initially identified 1666 articles. After reviewing all abstracts, 86 articles were identified as being significantly related to the diagnosis and management of interstitial pregnancies.

\section{Diagnosis}

Timely diagnosis is key to the successful management of patients with IPs. Diagnosing such cases may be difficult, due to the wide spectrum of presenting symptoms and signs and difficulties distinguishing an IP from an intra-uterine or isthmic tubal ectopic pregnancy. Also, some patients may present with rupture and haemodynamic instability requiring immediate surgery before a non-invasive diagnosis may be made. Patients may present with abdominal pain and/or vaginal bleeding, may be asymptomatic or have their IP diagnosed on routine early pregnancy scan.

Risk factors for IP include previous ectopic pregnancy, tubal surgery, in vitro fertilisation (IVF), ovulation induction, or history of sexually transmitted disease $[7,9,10]$ (Table 1). Hiersch et al. noted that $46 \%$ of the women with IPs treated in their hospital had conceived following assisted reproductive techniques [11]. With the incidence of IVF increasing, one expects a resultant increase in IPs. There does not appear to be a single risk factor that clearly differentiates patients with an IP from those with an ampullary or isthmic ectopic pregnancy [12].

Since the introduction of high-resolution transvaginal ultrasonography (TVUS) and highly sensitive $\beta$-hCG assays, timely and accurate diagnosis has become possible. There is no evidence of particular serum $\beta$-hCG trends that are sensitive in differentiating IPs from either normal intrauterine pregnancies or other types of ectopic pregnancies.

\section{Ultrasound diagnosis}

Ever-improving ultrasound technology has resulted in wider utilisation of ultrasound to diagnose gynaecological conditions. TVUS has been reported to have a sensitivity of $56 \%$ at 8.2 weeks' gestation [10], and $71.4 \%$ of patients at 6.9 weeks' gestation [7]. MacRae et al.'s study reported $80 \%$ of IPs being correctly diagnosed on 2D-TVUS scanning [13]. There is no evidence that 3D-US is more accurate for diagnosing IPs than 2D-US; however, it is easier to demonstrate the interstitial nature of the pregnancy on 3D than 2D.

The diagnosis of IP by ultrasound is based on the following criteria: the GS is located outside the uterine cavity; the interstitial part of Fallopian tube is seen adjoining the lateral aspect of the uterine cavity and GS; and the myometrial mantle extends laterally to encircle the GS (Fig. 2) [14].

Table 1 Risk factors for interstitial pregnancies

\begin{tabular}{ll}
\hline Risk factors & $\begin{array}{l}\text { Percentage of women with } \\
\text { an IP who have this risk factor }\end{array}$ \\
\hline Previous ectopic pregnancy & $22.9-54 \%$ \\
$\begin{array}{l}\text { Previous ipsilateral or bilateral } \\
\text { salpingectomy }\end{array}$ & $22.9-54 \%$ \\
Conception after in vitro fertilisation & $17.1-34.4 \%$ \\
History of sexually transmitted disease & $12.5-25.0 \%$ \\
\hline
\end{tabular}




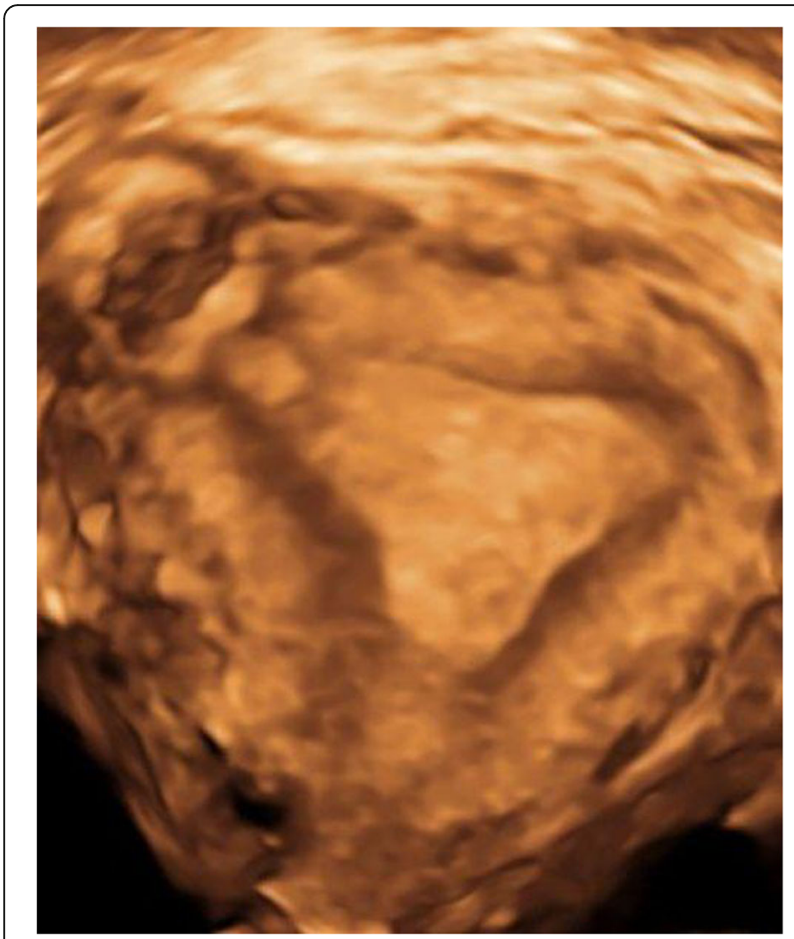

Fig. 2 US image of interstitial pregnancy

The fallopian tube's interstitial section is best evaluated in the transverse plane at the level of the uterine fundus and appears as a thin echogenic line extending from the lateral aspect of the endometrium toward the uterine serosa [15].

Magnetic resonance imaging (MRI) and surgical diagnosis MRI may be used in clinically stable patients whose diagnosis remains uncertain despite having a TVUS. However, referral to a tertiary centre with sufficient expertise in diagnosing and managing IPs may be preferable [16]. Despite the above advances in the radiological diagnosis of IP, a small cohort of patients will only be diagnosed with an IP at laparoscopy or laparotomy due to either the lack of sufficient ultrasound expertise or haemodynamic instability (Fig. 3).

\section{Management}

Historically, management of IPs included wedge resection by laparoscopic/open surgery or hysterectomy [3]. Less invasive and/or aggressive techniques may reduce the risk of intra-operative complications, whilst improving long-term fertility and obstetric outcomes. Table 2 illustrates the various management options and their associated benefits (in lighter grey) and drawbacks (in darker grey); we will discuss these options in detail below.

\section{Conservative management (expectant and medical management)}

The establishment of early pregnancy assessment units, use of high resolution TVUS and access to rapid quantitative $\beta$-hCG testing facilitate early detection of ectopic pregnancies, prior to tubal rupture [14]. Conservative management (encompassing expectant and medical management) should only be offered to patients with a radiologically diagnosed IP who are haemodynamically stable and have no obvious risks of immediate rupture, such as large GS or rapidly increasing $\beta$-hCG levels. Fastidious follow-up allows expectant or medical management to be offered as first line management in appropriate patients.

\section{Expectant management}

Spontaneous miscarriage is a common pregnancy outcome, whether the pregnancy is intra-uterine or ectopic [12]. Expectant management is an appropriate first line approach for women with an IP and declining serum $\beta$-hCG levels (irrespective of ectopic mass size and initial serum $\beta$-hCG levels) $[17,18]$. Expectant management should be abandoned if there is evidence of clinical deterioration.

Retrospective case series carried out by Cassik et al. and Poon et al. at King's College Hospital (London) reported a total of 26 cases which were initially offered expectant management (Table 3). Cassik et al. noted that there were no significant differences in success rates between expectant or medical management options $(P>$ $0.05)$ [14]. However, success rates for patients given local methotrexate $(21 / 23,91 \%)$ may have been higher than for expectant 5/7, 71\% (95\%CI 29-96) due to larger numbers of patients. The authors did not find any significant differences in either the initial $\beta$-hCG levels or $\beta$-hCG resolution times between the three subgroups. They did note that the initial serum $\beta$-hCG was significantly lower in cases of successful conservative treatment, with no failures occurring when the initial $\beta$-hCG was less than $9000 \mathrm{IU} / \mathrm{L}$. Poon et al. noted that the length of follow-up for those patients managed expectantly ranged from 7 to 141 days, with a median duration of 50.6 days [18]. Several other studies analysed expectant management, but the number of patients was too low to be able to detect significant differences in outcome $[16,19,20]$.

\section{Medical management of tubal ectopic pregnancy}

High dose intravenous/intramuscular methotrexate (MTX) with oral folic acid rescue was first proposed as a safe alternative for the management of IP in 1982 [21] (Table 4). The dose of one-off systemic MTX is calculated according to the Stovall et al. protocol: 50 $\mathrm{mg} / \mathrm{m}^{2}$ body surface area [22]. 


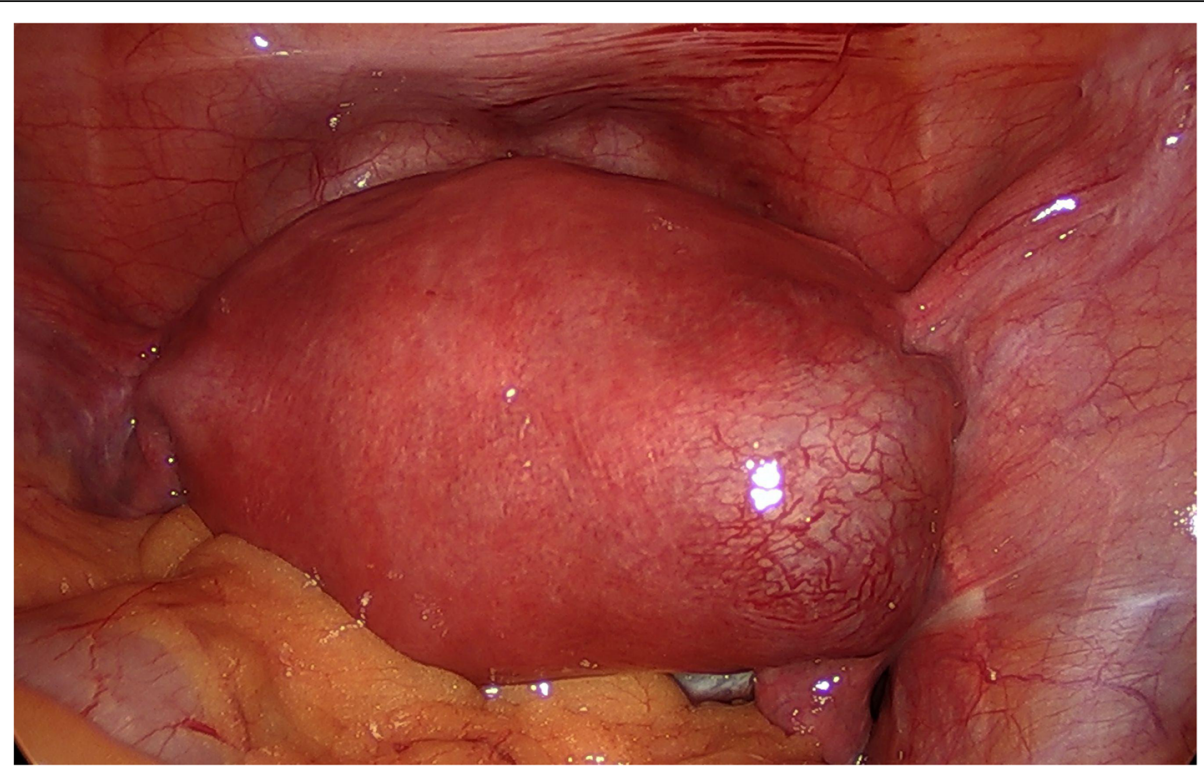

Fig. 3 Laparoscopic view of interstitial pregnancy

Systemic MTX is now widely used as the first-line management for patients with tubal ectopic pregnancy who fulfil all the inclusion criteria [23]. An RCT comparing methotrexate with laparoscopic salpingostomy surgery for tubal ectopics showed that methotrexate is equally successful to salpingostomy in terms of requirement for further treatment [24]. However, current guidance is that for women with a normal contralateral tube salpingectomy is recommended due to the risk of ongoing trophoblast, increased bleeding and no proven different in future intra-uterine pregnancy rates [25]. Another RCT comparing single methotrexate with laparoscopic salpingostomy surgery concluded that single dose methotrexate was less effective than salpingostomy (65\% vs. 93\% respectively) [26]. However, RCTs comparing expectant management versus management with

Table 2 Benefits and drawbacks of modes of management used in IPS

\begin{tabular}{|c|c|c|c|c|c|c|c|}
\hline \multicolumn{8}{|c|}{ Benefits \& Drawbacks of Modes of Management used in IPs } \\
\hline $\begin{array}{l}\text { Expectant } \\
\text { management }\end{array}$ & $\begin{array}{l}\text { Systemic } \\
\text { methotrexate } \\
\text { (MTX) }\end{array}$ & $\begin{array}{l}\text { Loc } \\
\text { met } \\
\left(M^{\prime}\right.\end{array}$ & $\begin{array}{l}\text { al } \\
\text { hotrexate } \\
\text { X) }\end{array}$ & $\begin{array}{l}\text { US-guided D\&C / } \\
\text { transcervical } \\
\text { forceps extraction }\end{array}$ & $\begin{array}{l}\text { Laparoscopic } \\
\text { wedge } \\
\text { resection }\end{array}$ & $\begin{array}{l}\text { Laparoscopic } \\
\text { Cornuostomy }\end{array}$ & $\begin{array}{l}\text { Open surgical } \\
\text { management }\end{array}$ \\
\hline \multicolumn{4}{|c|}{ Need to satisfy strict inclusion criteria } & & \multicolumn{3}{|c|}{$\begin{array}{l}\text { Option for advanced cases not suited } \\
\text { for conservative management }\end{array}$} \\
\hline & \multicolumn{7}{|c|}{ Requires technical expertise } \\
\hline $\begin{array}{l}\text { Avoids side- } \\
\text { effects from } \\
\text { medical } \\
\text { management; } \\
\text { eliminates } \\
\text { surgical risks }\end{array}$ & \multicolumn{2}{|c|}{$\begin{array}{l}\text { Risk of side } \\
\text { effects from MTX }\end{array}$} & $\begin{array}{l}\text { Reduced } \\
\text { risk of } \\
\text { side } \\
\text { effects } \\
\text { from } \\
\text { MTX }\end{array}$ & & \multicolumn{3}{|c|}{$\begin{array}{c}\text { Risk of intra-operative and post-operative } \\
\text { complications }\end{array}$} \\
\hline \multicolumn{5}{|c|}{$\begin{array}{l}\text { Requires 24-hour availability of anaesthetists, } \\
\text { plus clinicians with adequate surgical expertise }\end{array}$} & \multicolumn{3}{|c|}{ Requirement of specialist facilities } \\
\hline \multicolumn{2}{|c|}{ Outpatient care } & \multicolumn{4}{|c|}{ May be performed as a day case } & & $\begin{array}{l}\text { Requires hospital } \\
\text { admission }\end{array}$ \\
\hline \multirow{2}{*}{\multicolumn{4}{|c|}{$\begin{array}{l}\text { Requires prolonged follow-up / hospitalisation } \\
\text { Unpredictable course }\end{array}$}} & & \multicolumn{3}{|c|}{ Reduced length of follow-up } \\
\hline & & & & & \multicolumn{3}{|c|}{ Definitive management } \\
\hline \multicolumn{4}{|c|}{ Non-invasive } & \multicolumn{3}{|c|}{ Minimally invasive } & Invasive \\
\hline \multicolumn{5}{|c|}{ Avoidance of uterine scar } & & & $\begin{array}{l}\text { Necessitates a } \\
\text { uterine scar }\end{array}$ \\
\hline
\end{tabular}


Table 3 Studies on expectant management on IPS

\begin{tabular}{|c|c|c|c|c|c|c|c|c|}
\hline Article & Location & $\begin{array}{l}\text { No. of } \\
\text { cases }\end{array}$ & $\begin{array}{l}\text { Patient age } \\
\text { (years) }\end{array}$ & $\begin{array}{l}\text { Gestation } \\
\text { (weeks) }\end{array}$ & $\begin{array}{l}\text { Diameter of } \\
\text { GS }(\mathrm{mm})\end{array}$ & $\begin{array}{l}\text { Foetal cardiac } \\
\text { activity present }\end{array}$ & $\beta-h C G$ & Comments \\
\hline $\begin{array}{l}\text { Cassik et al. } \\
2005 \text { [14] }\end{array}$ & $\begin{array}{l}\text { King's College } \\
\text { Hospital (London, UK) } \\
\text { [December } 1996 \text { to March 2003] }\end{array}$ & 7 & N/A & $7(4-13)$ & N/A & 0 & $\begin{array}{l}1799 \\
(438-11,460)\end{array}$ & $\begin{array}{l}71 \% \text { success rate }((95 \% \mathrm{Cl} 29-96) \\
\text { No significant differences in success } \\
\text { rates between the three different } \\
\text { management options }(P>0.05)\end{array}$ \\
\hline $\begin{array}{l}\text { Poon et al. } \\
2014 \text { [18] }\end{array}$ & $\begin{array}{l}\text { King's College Hospital } \\
\text { (London, UK) } \\
\text { [January } 2004 \text { to April 2013] }\end{array}$ & 19 & $\begin{array}{l}31.26 \\
(18-42)\end{array}$ & 10.1 & $19.0(9-49)$ & 0 & $\begin{array}{l}3468.0 \\
(157-89,968)\end{array}$ & $\begin{array}{l}\text { Overall success rate } 89.5 \%(n=17) \\
\text { Two failed cases were subsequently } \\
\text { treated with MTX. No cases of uterine } \\
\text { rupture. } \\
\text { Median follow-up } 50.6 \text { days }\end{array}$ \\
\hline
\end{tabular}

MTX did not find any significant benefit for pregnancies with $\beta$-hCG levels less than 1500 IU $[27,28]$.

\section{Medical management for interstitial ectopic pregnancy}

For IP, in addition to intravenous or intramuscular administration, MTX may also be injected locally either into, or close to, the GS (under TVUS or laparoscopic guidance). Doses for the local injection of MTX in the studies below ranged from 25 to $50 \mathrm{mg}$.

Cassik et al. [14] published a case series of conservatively managed IP. They found success rates for local methotrexate, systemic methotrexate and expectant management was $91 \%, 80 \%$ and $71 \%$ respectively although the numbers were too small to show a statistically significant difference [14]. However, the 5/35 $(14.3 \%)$ of the patients managed conservatively required surgical treatment, all of whom had $\beta$-hCG levels greater than $9000 \mathrm{IU} / \mathrm{L}$ [14].

Some authors advocate local injection of MTX or potassium chloride into the GS when foetal cardiac activity is present $[14,29]$ : our review did not find any evidence that this is beneficial in the management of IPs. Even though Cassik et al. had a higher success rate in the local MTX group than the systemic MTX group, this was not found to be significant $(P>0.05)$ [14]. Of note, local MTX administration is more invasive than systemic administration and requires special facilities and trained personnel; this makes it more operator-dependent, less widely available and more costly than systemic MTX administration. Local treatment can be administered under ultrasound guidance into the gestational sac/chorionic tissue, via transvaginal route using a fine spinal needle.

Table 4 Combined data from current studies on medical management of interstitial ectopic pregnancy

\begin{tabular}{|c|c|c|c|c|c|c|}
\hline Study & $\begin{array}{l}\text { Number of } \\
\text { patients in total }\end{array}$ & $\begin{array}{l}\text { Number of patients } \\
\text { successfully managed } \\
\text { (local and systemic } \\
\text { MTX) }\end{array}$ & $\begin{array}{l}\text { Number of } \\
\text { patients managed } \\
\text { with systemic } \\
\text { MTX }\end{array}$ & $\begin{array}{l}\text { Number of patients } \\
\text { successfully managed } \\
\text { (systemic MTX) }\end{array}$ & $\begin{array}{l}\text { Number of } \\
\text { patients managed } \\
\text { with local MTX }\end{array}$ & $\begin{array}{l}\text { Number of patients } \\
\text { successfully managed } \\
\text { (local MTX) }\end{array}$ \\
\hline $\begin{array}{l}\text { Hafner et al. } \\
1999 \text { [16] }\end{array}$ & 10 & 9 & 5 & 4 & 5 & 5 \\
\hline $\begin{array}{l}\text { Jermy et al. } \\
2004 \text { [20] }\end{array}$ & 18 & 14 & 18 & 14 & N/A & N/A \\
\hline $\begin{array}{l}\text { Tulandi et al } \\
2004 \text { [44] }\end{array}$ & 8 & 5 & N/A & N/A & N/A & N/A \\
\hline $\begin{array}{l}\text { Cassik et al. } \\
2005 \text { [8] }\end{array}$ & 28 & 24 & 5 & 4 & 23 & 21 \\
\hline $\begin{array}{l}\text { Tang et al. } \\
2006 \text { [42] }\end{array}$ & 11 & 10 & 11 & 10 & N/A & N/A \\
\hline $\begin{array}{l}\text { Surbone et al. } \\
2013 \text { [38] }\end{array}$ & 9 & 8 & 3 & 2 & 6 & 6 \\
\hline $\begin{array}{l}\text { Hiesch et al. } \\
2014 \text { [17] }\end{array}$ & 17 & 12 & 17 & 12 & N/A & N/A \\
\hline $\begin{array}{l}\text { Framarino et al. } \\
2014 \text { [15] }\end{array}$ & 14 & 14 & N/A & N/A & 14 & 14 \\
\hline $\begin{array}{l}\text { Tanaka et al. } \\
2015 \text { [40] }\end{array}$ & 33 & 31 & 33 & 31 & N/A & N/A \\
\hline Total & 148 & 127 & 92 & 77 & 48 & 46 \\
\hline $\begin{array}{l}\text { Success rate } \\
(95 \% \mathrm{Cl})\end{array}$ & & $85.81 \%(84.17-87.45)$ & & $79.98 \%(72.68-87.29)$ & & $97.83 \%$ (93.56-100) \\
\hline
\end{tabular}


This needle may be advanced through the anterior fornix, through the anterior uterine wall and into the targeted area where the MTX may be delivered straight into the gestational sac and surrounding area [14].

One proposed benefit of administering MTX locally (rather than systemically) is to reduce the incidence of side-effects, such as transitory peripheral neuropathy, severe constipation, and deterioration in liver function [30]. Significant side effects were documented in 2/5 (40\%) of women receiving systemic MTX in [14] study. Cassik and Hafner et al. noted that patients who received MTX injected locally into the GS did not experience any of these side effects; however, numbers were too low to show significance $[14,30]$.

The safety of MTX management of IP relies upon diligent follow-up and the capacity to perform expedient surgery if required. Close follow-up (such as that outlined above) is crucial, as $10-20 \%$ of patients will require either a second dose of MTX or surgery. Success rates in the studies included in this review were 85.81\% (95\%CI 84.17-87.45). Of note, different MTX regimens were used in these studies, including both systemic and local MTX injection: the average success rate for systemic MTX was 79.9\% (95\%CI $72.68-$ 87.29), whilst for local MTX injection, it was $97.83 \%$ (95\%CI 93.59-100). None of the studies reported any significant difference in the success rate between systemic and local MTX.

Our literature search did not identify the following factors as significantly affecting the efficacy of MTX management: initial $\beta$-hCG levels, GS size, gestation, maternal age, or foetal cardiac activity (Table 5). Hiersch et al. identified a higher rate of unsuccessful first-line treatment in women with two previous ectopic pregnancies $(4 / 5$ cases, $80 \%$ versus $1 / 12$ cases; $8.3 \% ; P=0.01$ ) [11].

In Jermy et al.'s study, all patients with an initial serum $\beta$-hCG $<5000$ were managed successfully with a single dose of systemic MTX [6] (Table 6). The key indicators of failed MTX management were insufficient reduction in $\beta$-hCG levels, abdominal pain, or rupture. $2.4 \%$ of the 167 cases experienced a ruptured ectopic pregnancy, requiring emergency surgery. The mean time taken for $\beta$-hCG levels to normalise was 47.93 days. The duration of hospital stay varied considerably, with some patients being managed as outpatients and others as inpatients: one patient was admitted for 40 days.

Patients with continuously rising $\beta$-hCG levels warrant closer surveillance, such as sonographic evaluation for signs of pregnancy progression (e.g. the development of foetal cardiac activity) or uterine/tubal rupture. Repeated MTX dosing should be considered until one is satisfied that the IP has been resolved.

\section{Surgical management}

Surgical management of IPs remains an important option, as it offers definitive treatment (Table 7). Historically, wedge resection or hysterectomy by laparotomy was the mainstays of surgical management; however, the morbidity associated with such invasive operations has led to newer, less invasive techniques being preferred.

Women with IPs who are haemodynamically unstable and/or have an ultrasound suggestive of pregnancy rupture should undergo immediate surgical management. Patients who present with heterotopic pregnancies (one of which is both viable and wanted) should be offered surgical rather than expectant management as accurate monitoring with $\beta$-hCG levels is not possible in this situation.

Advances in laparoscopic surgery allow for less invasive and less traumatic surgical options for patients with IPs than those practised historically (i.e. laparoscopic cornual resection, rather than abdominal hysterectomy). While cornual ('wedge') resection preserves patients' future fertility, it may carry the risk of uterine rupture due to the loss of myometrium and extensive uterine scarring $([31]$,$) . Liao et al. reported an incidence of subse-$ quent uterine rupture and dehiscence after wedge resection of $30 \%$ [32]. This is considerably higher than the uterine rupture rates post myomectomies, which typically range from 0.49 to $0.70 \%$ in subsequent pregnancies [32] However, an alternate study has not shown increased risk of uterine rupture in subsequent pregnancy although, in this cohort, the caesarean rate was $60 \%$ versus $30 \%$ of patients without a history of ectopic pregnancy $(P=0.137)$ [33].

More recent studies favour cornuostomy over cornual resection. Cornuostomy excises the IP, while preserving uterine architecture and maintaining fertility ([34]). Cornuostomy is considered to cause less tubal damage than cornual resection and may have better pregnancy outcomes in future (including fewer cases of uterine rupture) [32]. The risk of persistent ectopic pregnancy (i.e. failed initial management) after laparoscopic salpingostomy in tubal pregnancies has been reported to be 5$20 \%$ [35]); however, our review found a $99.16 \%(95 \% \mathrm{CI}$ 97.51-100) success rate in patients with IPs who underwent cornuostomy. Risk factors for recurrent IP following salpingostomy/cornuostomy include an IP $<2 \mathrm{~cm}$ and rapidly rising pre-operative $\beta$-hCG [36]. The smaller the gestational sac, the harder it is to ensure that the entire interstitial pregnancy has been excised, thereby increasing the risk of persistent interstitial pregnancy [37]. A larger ectopic pregnancy does not appear to be an indication for cornual resection (rather than cornuostomy): MacRae et al. and Watanabe et al. performed cornuostomies for larger interstitial GSs [13, 38]. However, this conflicts with the advice given by Cucinella 


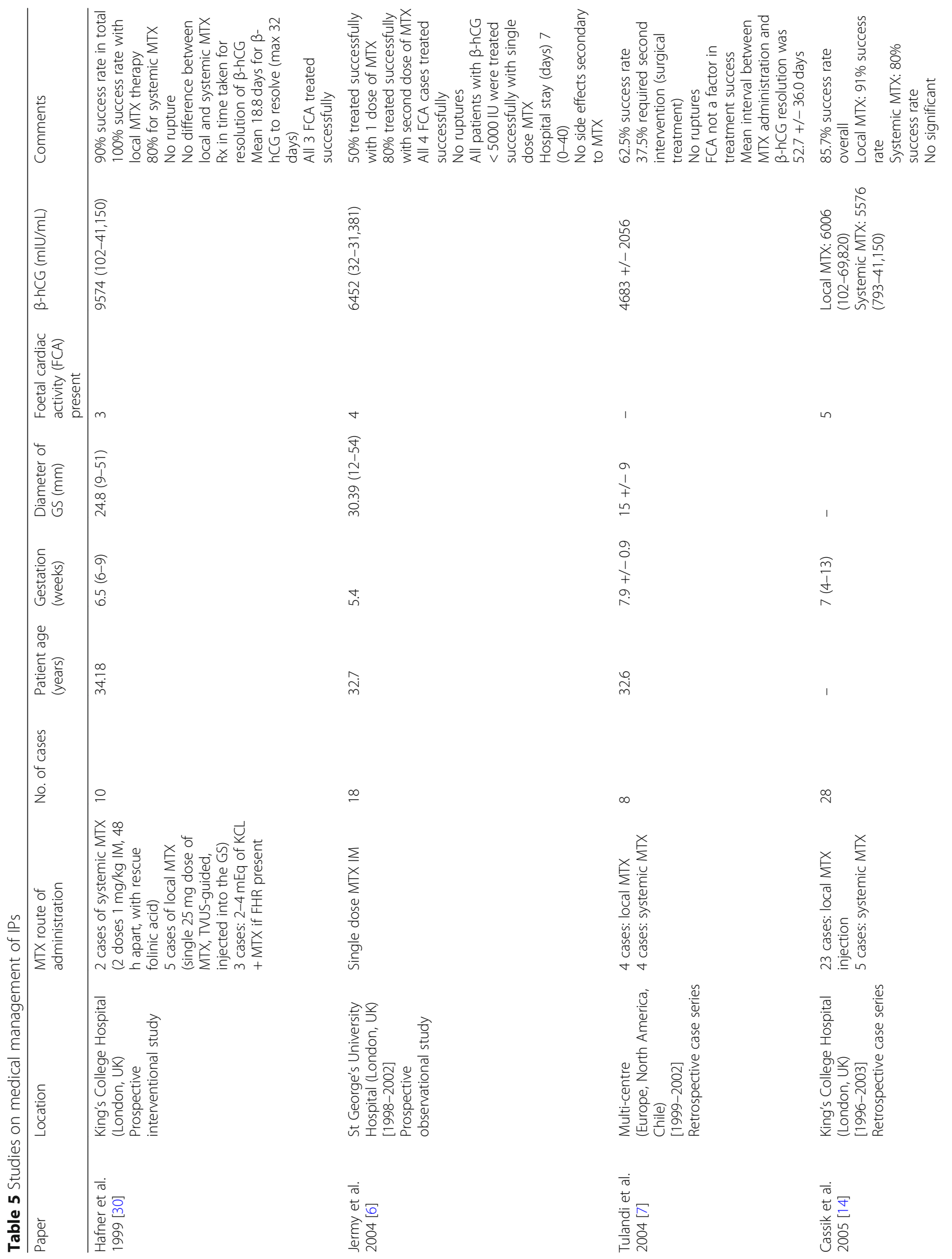




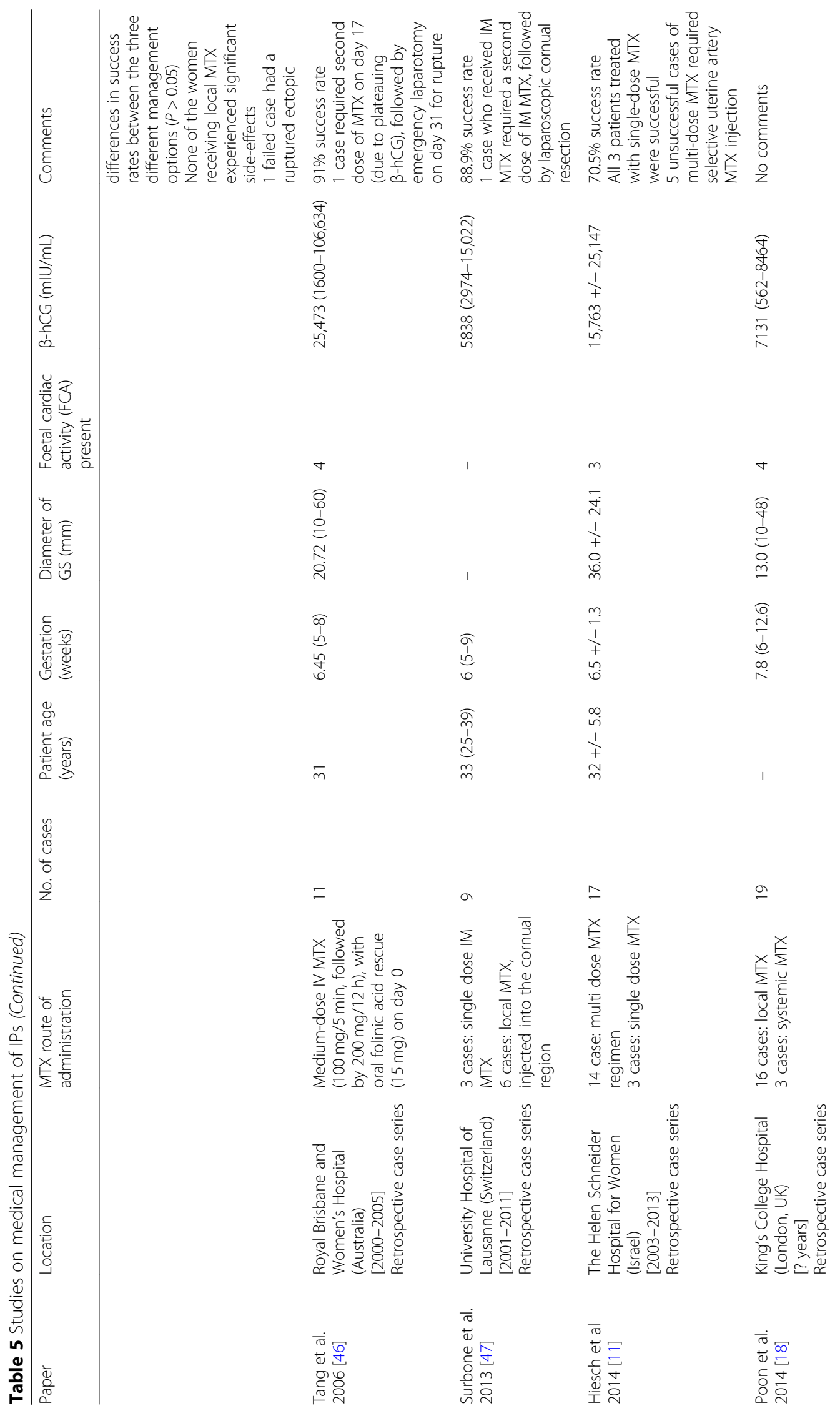




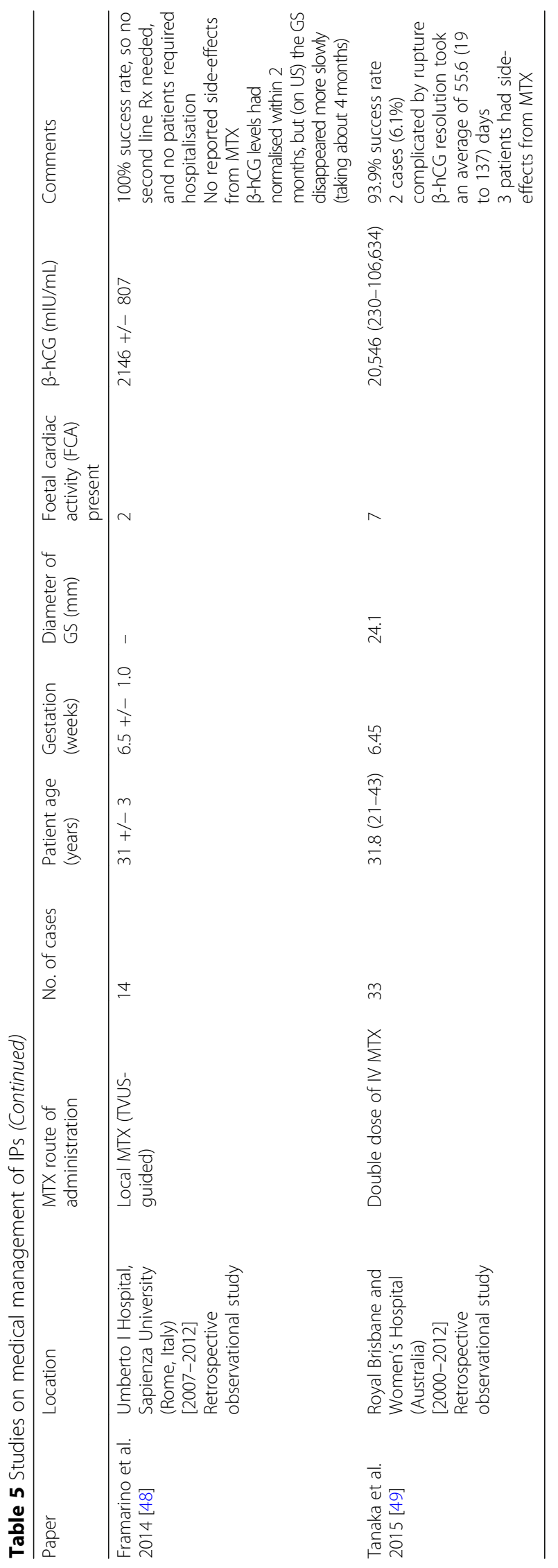


Table 6 Combined data from current studies on surgical management of interstitial ectopic pregnancy

\begin{tabular}{|c|c|c|c|c|c|c|}
\hline Study & $\begin{array}{l}\text { Number of } \\
\text { patients in total }\end{array}$ & $\begin{array}{l}\text { Success rate of combined } \\
\text { (cornuostomy/cornual } \\
\text { resection) }\end{array}$ & $\begin{array}{l}\text { Number of patients } \\
\text { treated by cornuostomy }\end{array}$ & $\begin{array}{l}\text { Success rate of } \\
\text { cornuostomies }\end{array}$ & $\begin{array}{l}\text { Number of patients } \\
\text { treated by cornual } \\
\text { resection }\end{array}$ & $\begin{array}{l}\text { Success rate of } \\
\text { cornual resection }\end{array}$ \\
\hline $\begin{array}{l}\text { Moon et al. } \\
2000 \text { [41] }\end{array}$ & 24 & 23 & 24 & 23 & N/A & N/A \\
\hline $\begin{array}{l}\text { Tulandi et al. } \\
2004 \text { [7] }\end{array}$ & 24 & 23 & 3 & 3 & 21 & 20 \\
\hline $\begin{array}{l}\text { Choi et al. } \\
2009 \text { [50] }\end{array}$ & 8 & 8 & 8 & 8 & N/A & N/A \\
\hline $\begin{array}{l}\text { Moon et al. } \\
2010 \text { [37] }\end{array}$ & 20 & 20 & 20 & 20 & N/A & N/A \\
\hline $\begin{array}{l}\text { Watanabe et al. } \\
2014 \text { [38] }\end{array}$ & 13 & 13 & 13 & 13 & N/A & N/A \\
\hline $\begin{array}{l}\text { Liao et al. } \\
2016 \text { [32] }\end{array}$ & 29 & 29 & N/A & N/A & 29 & 29 \\
\hline $\begin{array}{l}\text { Nirgianakis et al. } \\
2017 \text { [43] }\end{array}$ & 10 & 10 & N/A & N/A & 10 & 10 \\
\hline Total & 128 & 126 & 68 & 67 & 60 & 59 \\
\hline $\begin{array}{l}\text { Success rate } \\
(95 \% \mathrm{Cl})\end{array}$ & & $98.1 \%$ (95.48-100) & & $99.16 \%(97.51-100)$ & & $98.41 \%(95.30-100)$ \\
\hline
\end{tabular}

N/A implies that the particular study did not consider patients managed with that treatment

who notes that cornual resection was preferred in cases of advanced gestational age and/or when ectopic size was $>4 \mathrm{~cm}$ in diameter [34]. Our experience is that with intra-myometrial vasopressin use for haemostasis, large and small IP can be treated laparoscopically.

Wedge resection disrupts the uterine architecture and should only be performed in cases of ruptured IP with troublesome bleeding or for patients not desiring future fertility. Similar operations (such as myomectomy) carry a risk of uterine rupture in subsequent pregnancies of $0.49-0.70 \%$ [39]: cornual resection is an accepted risk factor for uterine rupture in subsequent pregnancies [40] Cucinella et al.'s systematic review compared 156 cases of cornuostomy with 198 cases of cornual resection: the pregnancy rates in a small sample of these cases were $72 \%$ vs. $62 \%$ respectively, of which the live birth rates $48 \%$ vs. $62 \%$ in the cornuostomy and cornual resection groups, respectively. Any differences in the fertility outcomes or live birth rates between the two groups were not statistically significant [34].

Key steps in laparoscopic cornuostomy include cornual incision, removal of the products of conception, cornual repair and confirming haemostasis [41]. Prior to cornual incision, various methods to reduce intra-operative blood loss can be employed: vasopressin injection into peri-cornual area, electric cauterisation of incision area, endo-loop application to create a para-cornual tourniquet and an encircling suture around the cornu. There are concerns that electrocoagulation may damage the underlying myometrium and interfere with the revascularisation process, therefore weakening the area and theoretically increasing the risk of uterine rupture in future [37]; electrocauterisation also increases the risk of damage to surrounding organs, leading to injuries such as bowel perforation. Moon et al. concluded that the endo-loop and encircling suture methods are simple, safe, effective and nearly bloodless in achieving haemostatic control during treatment of IPs [37].

If possible, one should manage IPs using a minimally invasive approach, rather than open surgery. Tulandi et al. found that the mean volume of intra-abdominal haemorrhage encountered for the laparotomy group was $1385.7+/-978.8$ $\mathrm{ml}$, compared to $460.0+/-70.7 \mathrm{ml}$ for the laparoscopy group ( $P$ value-is this significant) [7]; this difference probably reflects surgeons' pre-operative decision-making (taking into account patients' differing pre-operative blood loss or haemodynamic stability), rather than blood loss caused by the operative technique itself. Hwang et al. assessed 88 cases of cornual resection, performed by either laparoscopy or laparotomy: the only significant difference found between the two groups was the duration of post-operative recovery [42]. The post-operative pain, length of hospital stay, return to normal function, return to work and cosmetic advantages of a laparoscopic approach should also be considered. Nirgianakis et al. noted similar rates of surgical complications $(P=0.413)$ and the need for subsequent MTX treatment $(P=0.513)$ in patients with an IP treatment with laparoscopic cornual resection, compared to women with tubal ectopic pregnancies treated with laparoscopic salpingectomy/salpingostomy [43].

\section{Other management options}

Ultrasound-guided transcervical forceps extraction (UTCE) As described by Ahn et al 2013, UTCE utilises a natural orifice to remove any products of conception [44]. The 


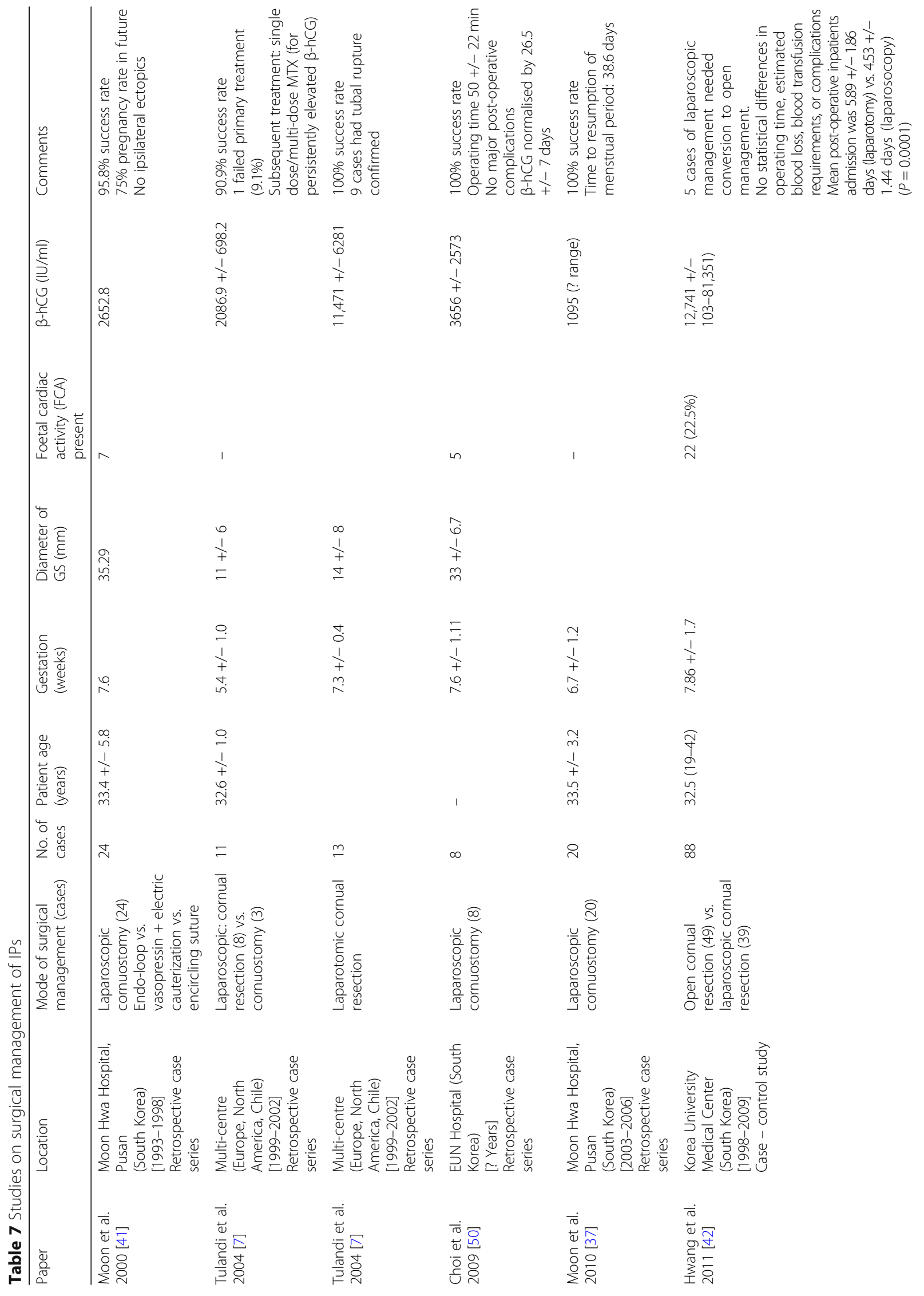




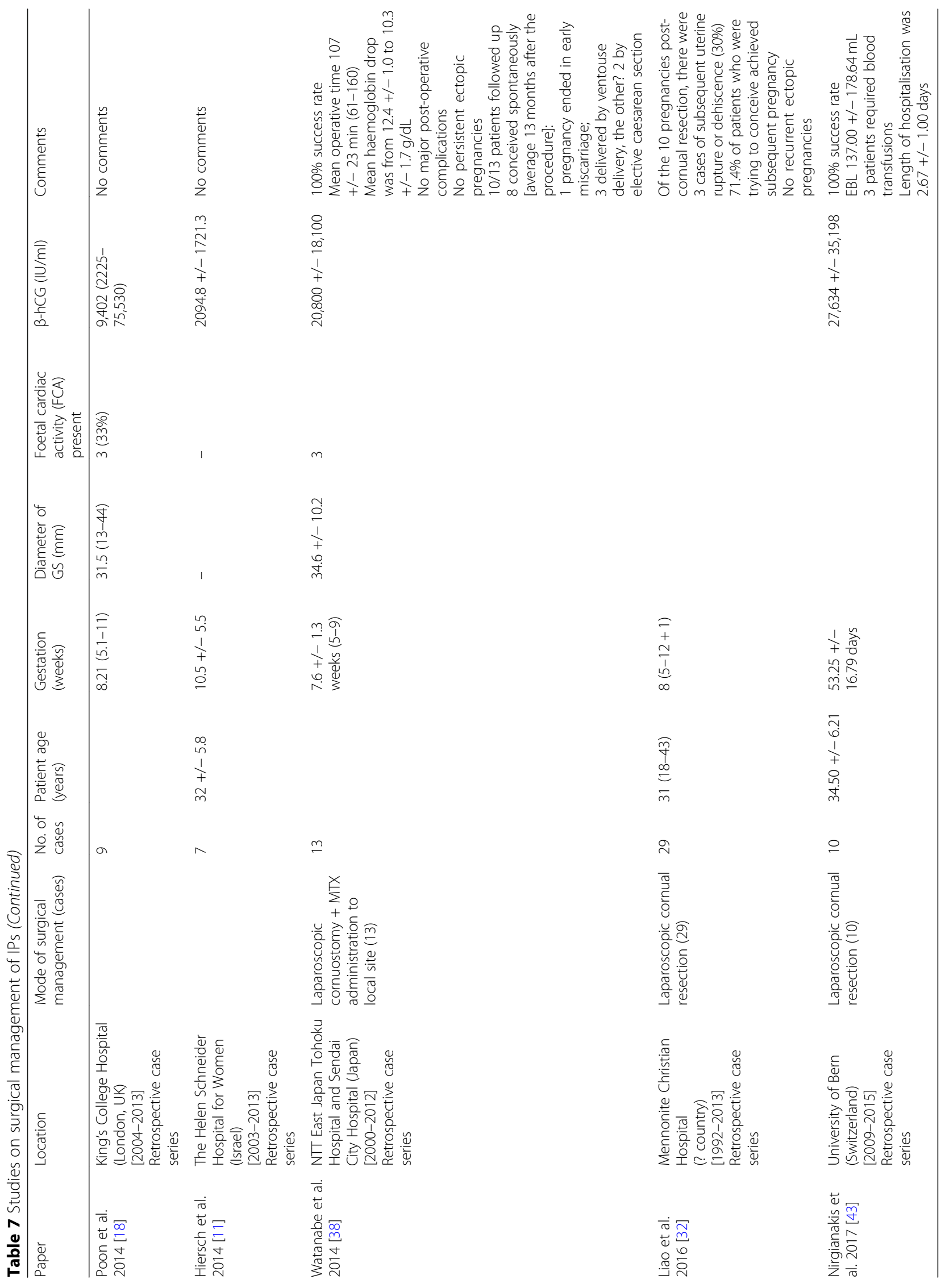


IP is approached through the vagina and cervical canal, then the GS is removed using small forceps (presumably through the tubal ostium), under transabdominal US guidance [44]).

Ahn et al. conducted a retrospective review of all IPs diagnosed between 1 March 2008 and 31 December 2011 at Ulsan University Hospital (South Korea). Six of the 16 IPs were managed by UTCE; these women were all haemodynamically stable at diagnosis. Five of these patients were treated successfully; one required further management. No patients had serious complications; the average drop in haemoglobin was $1.7 \mathrm{~g} / \mathrm{dL}(0.3-2.2 \mathrm{~g} /$ $\mathrm{dL}$ ). Three women went on to have successful pregnancies. The small number of patients and low power of this study means that statistically significant results cannot be easily inferred. The authors state that a potential benefit is that UTCE does not breach (and therefore weaken) the myometrium, as no incision into the myometrium is needed; however, we believe that management of IPs by this procedure would be difficult to achieve without damage to the myometrium.

\section{Transcervical suction under laparoscopic and hysteroscopic guidance}

An alternative to UTCE is transcervical suction under laparoscopic and hysteroscopic guidance. Cai et al. described how seven IPs of $>2 \mathrm{~mm}$ size were removed using a flexible $8 \mathrm{~F}$ paediatric suction catheter introduced transvaginally [45]. However, two of their seven suffered from a uterine perforation and increased blood loss $(>500 \mathrm{ml})$. These complications necessitated subsequent surgical management.

\section{Conclusion}

The diagnosis and management of interstitial pregnancies remains challenging, in part due to the rarity of these cases and the paucity of evidence to guide management. The high sensitivity of US, when sufficient expertise is available, makes it the best first line investigation that one may use to diagnose IPs.

IPs should be managed in early pregnancy units that have experience in managing such cases. Conservative management (encompassing expectant and medical management) should only be offered to patients with a radiologically diagnosed IP, who are haemodynamically stable and have no obvious risks of immediate rupture, such as large gestational sac or rapidly increasing $\beta$-hCG levels. Expectant management is an appropriate first line approach for women with an IP and declining serum $\beta$-hCG levels (irrespective of ectopic mass size and initial serum $\beta$-hCG levels) $[17,18]$. Expectant management should, however, be abandoned if there is any evidence of clinical deterioration. MTX has been advocated widely in the literature; however, much of the safety data is from retrospective cohort studies which may be susceptible to selection bias. The success rates for MTX management vary from $79.9 \%$ for systemic MTX to $97.83 \%$ for local MTX injection; however, the numbers in these studies were small. It needs to be remembered that failure of medical management resulting in rupture may have catastrophic consequences. For this reason, surgical management with a likely higher success rate $(99.16 \%)$ is becoming more popular in centres with sufficient experience. Laparoscopic cornuostomy is preferable to wedge resection due to the decreased intra-operative blood loss, reduced distortion of uterine anatomy and possible reduction in the risk of uterine rupture in subsequent pregnancies.

Further studies using prospective data from multiple centres are required to assess the impact of the various management options on the short term complications and long term outcomes such as fertility and pregnancy/ labour complications.

\section{Abbreviations \\ GS: Gestational sac; IP: Interstitial pregnancy; IVF: In vitro fertilisation; MRI: Magnetic resonance imaging; MTX: Methotrexate; RCT: Randomised control trial; TVUS: Transvaginal ultrasound scan; UTCE: Ultrasound-guided transcervical forceps extraction; $\beta$-hCG: Beta human chorionic gonadotrophin}

\section{Funding}

Not funded

\section{Disclosure statement}

The authors declare that they have no conflicts of interest and nothing to disclose.

\section{Authors' contributions}

MB contributed to the study conception, performed the searches, reviewed titles and abstracts, reviewed full text articles, extracted data, performed data analysis and drafted the manuscripts. AB-S contributed to the study conception review of full-text articles and data analysis as well as reviewed the manuscript for important intellectual content. TKH contributed to the study conception, providing clinical expertise on interstitial pregnancies, and reviewed the manuscript for important intellectual content. All authors read and approved the final manuscript

Ethics approval and consent to participate

Not required

\section{Consent for publication}

Not required

Competing interests

The authors declare that they have no competing interests.

\section{Publisher's Note}

Springer Nature remains neutral with regard to jurisdictional claims in published maps and institutional affiliations.

Received: 28 September 2018 Accepted: 28 December 2018

Published online: 04 February 2019

References

1. Wright SD, Busbridge RC, Gard GB (2013) A conservative and fertility preserving treatment for interstitial ectopic pregnancy. Aust N Z J Obstet Gynaecol 53(2):211-213. https://doi.org/10.1111/ajo.12067 
2. Mallick R, Ajala T (2016) A new technique in the laparoscopic resection of cornual ectopic pregnancies: a case series. Gynecol Surg:147-151. https:// doi.org/10.1007/s10397-016-0950-8

3. Lau, S. and Tulandi, T. (1999) 'Conservative medical and surgical management of interstitial ectopic pregnancy. [Review] [54 refs]', Fertil Steril, 72(2), pp. 207-215. Available at: http://ovidsp.ovid.com/ovidweb.cgi?T= JS\&CSC=Y\&NEWS=N\&PAGE=fulltext\&D=med4\&AN=10438980\%5Cn, http:// sfxeu07.hosted.exlibrisgroup.com/bham?sid=OVID:medline\&id=pmid: 10438980\&id=doi:\&issn=0015-0282\&isbn=\&volume=72\&issue=2\&spage= 207\&pages $=207-15 \&$ date $=1999 \&$ title $=F$

4. David DE (1992) Te Linde's operative gynecology. JAMA 267(21):2961. https://doi.org/10.1001/jama.1992.03480210123049

5. Chan LYS, Fok WY, Yuen PM (2003) Pitfalls in diagnosis of interstitial pregnancy. Acta Obstet Gynecol Scand 82(9):867-870. https://doi.org/10. 1034/j.1600-0412.2003.00214.x

6. Jermy K et al (2004) The conservative management of interstitial pregnancy BJOG Int J Obstet Gynaecol 111(11):1283-1288. https://doi.org/10.1111/j. 1471-0528.2004.00442.x

7. Tulandi T, Al-Jaroudi D (2004) Interstitial pregnancy: results generated from the society of reproductive surgeons registry. Obstet Gynecol 103(1):47-50. https://doi.org/10.1097/01.AOG.0000109218.24211.79

8. Buster JE, Heard MJ (2000) Current issues in medical management of ectopic pregnancy. Current Opinion in Obstetrics and Gynecology. 12(6): 525-527

9. Bayyarapu VB, Gundabattula SR (2017) Diagnosis and management of "cornual" pregnancies from 2002 to 2015 at a tertiary referral centre in South India: insights from introspection. J Obstet Gynaecol India 67(6):414-420. https://doi.org/10.1007/s13224-017-0983-6

10. Soriano D et al (2008) Laparoscopic treatment of cornual pregnancy: a series of 20 consecutive cases. Fertil Steril 90(3):839-843. https://doi.org/10. 1016/j.fertnstert.2007.07.1288

11. Hiersch $L$ et al (2014) Effectiveness of medical treatment with methotrexate for interstitial pregnancy. Aust N Z J Obstet Gynaecol 54(6):576-580. https:// doi.org/10.1111/ajo.12251

12. Moawad NS et al (2010) Current diagnosis and treatment of interstitial pregnancy. Am J Obstet Gynecol 202(1):15-29. https://doi.org/10.1016/j. ajog.2009.07.054

13. MacRae $R$ et al (2009) Diagnosis and laparoscopic management of 11 consecutive cases of cornual ectopic pregnancy. Arch Gynecol Obstet 280(1):59-64. https://doi.org/10.1007/s00404-008-0872-4

14. Cassik P et al (2005) Factors influencing the success of conservative treatment of interstitial pregnancy. Ultrasound Obstet Gynecol 26(3):279-282. https://doi. org/10.1002/uog.1961

15. Timor-Tritsch IE et al (1992) Sonographic evolution of cornual pregnancies treated without surgery. Obstet Gynecol:1044-1049. Available at: http:// www.ncbi.n/m.nih.gov/pubmed/1579304

16. Bourdel N et al (2007) Grossesse interstitielle. Diagnostic échographique et apport de l'IRM. A propos d'un cas. Gynecol Obstet Fertil 35(2):121-124. https://doi.org/10.1016/j.gyobfe.2006.06.023

17. Maymon R, Shulman A (1996) Controversies and problems in the current management of tubal pregnancy. Hum Reprod Update:541-551. https://doi. org/10.1093/humupd/2.6.541

18. Poon LCY et al (2014) How feasible is expectant management of interstitial ectopic pregnancy? Ultrasound Obstet Gynecol 43(3):317-321. https://doi. org/10.1002/uog.12565

19. Al Memar M, Touqmatchi D, Kothari A (2013) Is laparoscopy always the gold standard for diagnosis of ectopic pregnancies? BJOG Int J Obstet Gynaecol 120:546-547

20. Athansias P, Psychoulis M, Hayes K (2011) Management of interstitil pregnancies. Conservative treatment as a reliable alternative to surgery. Gynecol Surg 8

21. Tanaka T et al (1982) Treatment of interstitial ectopic pregnancy with methotrexate: report of a successful case. Fertil Steril 37(6):851-852. https:// doi.org/10.1016/S0015-0282(16)46349-1

22. Stovall TG, Ling FW, Gray LA (1991) Single-dose methotrexate for treatment of ectopic pregnancy. Obstet Gynecol 77(5):754-757

23. Elson CJ, Salim R, Potdar N, Chetty M, Ross JA, Kirk EJ, on behalf of the Royal College of Obstetricians and Gynaecologists (2016) Diagnosis and management of ectopic pregnancy. BJOG 123:e15-e55

24. Saraj AJ, Wilcox JG, Najmabadi S, Stein SM, Johnson MB, Paulson RJ (1998) Resolution of hormonal markers of ectopic gestation. a randomized trial comparing single-dose intramuscular methotrexate and salpingostomy. Obstet Gynecol 92:989-994

25. Mol F, Van Mello NM, Strandell A, Strandell K, Jurkovic D, Ross J, Barnhart KT, Yalcinkaya TM, Verhoeve HR, Graziosi GCM, Koks CAM, Klinte I, Hogstrom L, Janssen ICAH, Kragt H, Hoek A, Timbos-Kemper CM, Broakmans FJM, Hajenius PJ (2014) Salpingotomy versus salpingectomy in women with tubal pregnancy (ESEP study): an open-label multicenter, randomised controlled trial. Lancet 383(9927):1483-1489

26. Sowter MC, Farquhar CM, Petries KJ, Gudex G (2001) A randomised trial comparing single dose systemic methotrexate and laparoscopic surgery for the treatment of unruptured tubal pregnancy. BJOG 108:192-203

27. Jurkovic D, Memtsa M, Sawyer E, Donaldson A, Jamil A, Schram K, et al (2016) Single-dose systemix methotrexate vs expectant management for treatment of tubal ectopic pregnancy: a placebo-controlled randomised trial. Obstet Gynecol 49(2)

28. Van Mello NM, Mol F, Verhoeve HR, Van Wely M, Adriaanse AH, Boss EA, et a (2012) Methotrexate or expectant management in women with an ectopic pregnancy or pregnancy of unknown location and low serum hCG concentrations? A randomised comparison. Hum Reprod 28(2):60-67

29. Verma U, English D, Brookfield K (2011) Conservative management of nontubal ectopic pregnancies. Fertil Steril 96(6). https://doi.org/10.1016/j. fertnstert.2011.09.021

30. Hafner T et al (1999) The effectiveness of non-surgical management of early interstitial pregnancy: a report of ten cases and review of the literature. Ultrasound Obstet Gynecol 13:131-136. https://doi.org/10.1046/j.1469-0705. 1999.13020131.x

31. Weissman A, Fishman A (1992) Uterine rupture following conservative surgery for interstitial pregnancy. Eur J Obstet Gynecol Reprod Biol 44(3): 237-239. https://doi.org/10.1016/0028-2243(92)90105-8

32. Liao CY et al (2017) Cornual wedge resection for interstitial pregnancy and postoperative outcome. Aust N Z J Obstet Gynaecol 57(3):342-345. https:// doi.org/10.1111/ajo.12497

33. Hoyos L, Vilchez G, Allsworth JE, Malik M (2018) Outcomes in subsequent pregnancies after wedge resection for interstitial ectopic pregnancy: a retrospective cohort study. J Matern Fetal Neonatal Med. https://doi.org/10. 1080/14767058.2018.1437411

34. Cucinella G et al (2014) Interstitial pregnancy: a 'road map' of surgical treatment based on a systematic review of the literature. Gynecol Obstet Investig 78:141-149

35. Flystra D (1998) Tubal pregnancy: a review of current diagnosis and treatment. Obstet Gynecol Surv 1:122-126

36. Kemmann E, Trout S, Garcia A (1994) Can we predict patients at risk for persistent ectopic pregnancy after laparoscopic salpingotomy? Am Assoc Gynecol Laparosc 1(2):122-126. https://doi.org/10.1016/S1074-3804(05)80774-1

37. Moon HS et al (2010) Efficacy of bleeding control using a large amount of highly diluted vasopressin in laparoscopic treatment for interstitial pregnancy. Am J Obstet Gynecol 203(1):30.e1-30.e6. https://doi.org/10.1016/ j.ajog.2010.02.030

38. Watanabe T et al (2014) Laparoscopic cornuotomy for interstitial pregnancy and postoperative course. J Obstet Gynaecol Res 40(8):1983-1988. https:// doi.org/10.1111/jog.12422

39. Spong CY et al (2011) Timing of indicated late-preterm and early-term birth Obstet Gynecol:323-333. https://doi.org/10.1097/AOG.0b013e3182255999

40. Wang PH et al (1999) Primary repair of cornual rupture occurring at 21 weeks gestation and successful pregnancy outcome. Hum Reprod 14(7): 1894-1895. https://doi.org/10.1093/humrep/14.7.1894

41. Moon HS et al (2000) New simple endoscopic operations for interstitial pregnancies. Am J Obstet Gynecol 182(1):114-121. https://doi.org/10.1016/ S0002-9378(00)70499-6

42. Hwang JH et al (2011) Open cornual resection versus laparoscopic cornual resection in patients with interstitial ectopic pregnancies. Eur J Obstet Gynecol Reprod Biol 156(1):78-82. https://doi.org/10.1016/j.ejogrb.2010.12.014

43. Nirgianakis K et al (2017) Laparoscopic management of ectopic pregnancies: a comparison between interstitial and "more distal" tubal pregnancies. Arch Gynecol Obstet 295(1):95-101. https://doi.org/10.1007/s00404-016-4191-x

44. Ahn JW et al (2013) Ultrasound-guided transcervical forceps extraction of unruptured interstitial pregnancy. BJOG Int J Obstet Gynaecol 120(10):1285-1288. https://doi.org/10.1111/1471-0528.12265

45. Cai $Z$ et al (2012) The value of laparoscopy alone or combined with hysteroscopy in the treatment of interstitial pregnancy: analysis of 22 cases. Arch Gynecol Obstet 285(3):727-732. https://doi.org/10.1007/s00404-011-2060-1 
46. Tang A, Baartz D, Khoo SK (2006) A medical management of interstitial ectopic pregnancy: a 5-year clinical study. Aust N Z J Obstet Gynaecol 46(2): 107-111. https://doi.org/10.1111/j.1479-828X.2006.00537.x

47. Surbone A et al (2013) Interstitial pregnancies' diagnosis and management: an eleven cases series. Swiss Med Wkly 143(February):1-9. https://doi.org/10. 4414/smw.2013.13736

48. Framarino-dei-Malatesta M et al (2014) Transabdominal ultrasound-guided injection of methotrexate in the treatment of ectopic interstitial pregnancies. J Clin Ultrasound 42(9):522-526. https://doi.org/10.1002/jcu. 22185

49. Tanaka K, Baartz D, Khoo SK (2015) Management of interstitial ectopic pregnancy with intravenous methotrexate: an extended study of a standardised regimen. Aust N Z J Obstet Gynaecol 55(2):176-180. https:// doi.org/10.1111/ajo.12315

50. Choi YS et al (2009) Laparoscopic cornuotomy using a temporary tourniquet suture and diluted vasopressin injection in interstitial pregnancy. Fertil Steril 91(5):1933-1937. https://doi.org/10.1016/j.fertnstert.2008.02.013

\section{Submit your manuscript to a SpringerOpen ${ }^{\circ}$ journal and benefit from:}

- Convenient online submission

- Rigorous peer review

- Open access: articles freely available online

- High visibility within the field

- Retaining the copyright to your article

Submit your next manuscript at $\boldsymbol{\nabla}$ springeropen.com 